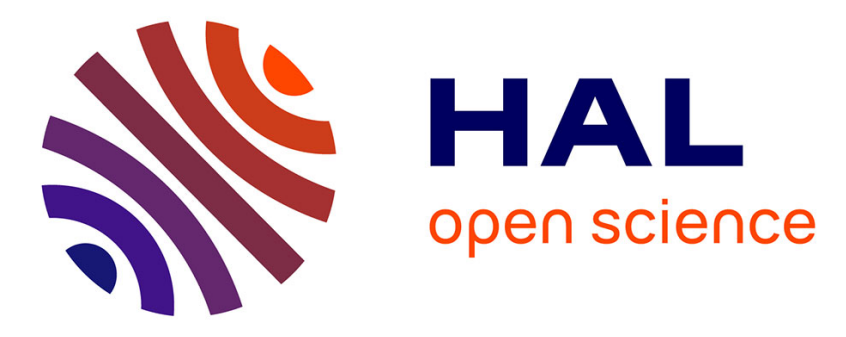

\title{
Purification of Ge-As-Se ternary glasses for the development of high quality microstructured optical fibers
}

Marcello Meneghetti, Celine Caillaud, Radwan Chahal, Elodie Galdo, Laurent Brilland, Jean-Luc Adam, Johann Troles

\section{To cite this version:}

Marcello Meneghetti, Celine Caillaud, Radwan Chahal, Elodie Galdo, Laurent Brilland, et al.. Purification of Ge-As-Se ternary glasses for the development of high quality microstructured optical fibers. Journal of Non-Crystalline Solids, 2019, 503-504, pp.84-88. 10.1016/j.jnoncrysol.2018.09.028 . hal-01944063

HAL Id: hal-01944063

https://hal-univ-rennes1.archives-ouvertes.fr/hal-01944063

Submitted on 4 Dec 2018

HAL is a multi-disciplinary open access archive for the deposit and dissemination of scientific research documents, whether they are published or not. The documents may come from teaching and research institutions in France or abroad, or from public or private research centers.
L'archive ouverte pluridisciplinaire HAL, est destinée au dépôt et à la diffusion de documents scientifiques de niveau recherche, publiés ou non, émanant des établissements d'enseignement et de recherche français ou étrangers, des laboratoires publics ou privés. 


\title{
Purification of Ge-As-Se ternary glasses for the development of high quality microstructured optical fibers
}

\author{
Marcello Meneghetti ${ }^{1}$, Celine Caillaud ${ }^{2}$, Radwan Chahal ${ }^{2}$, Elodie Galdo ${ }^{1}$, Laurent Brilland ${ }^{2}$, Jean-Luc Adam ${ }^{1}$, \\ Johann Troles 1 \\ ${ }^{1}$ Univ Rennes, CNRS, ISCR - UMR 6226 F-35000 Rennes, France \\ ${ }^{2}$ SelenOptics, 263 Avenue $G^{\text {al }}$ Leclerc, 35042 Rennes, France
}

\begin{abstract}
The production of chalcogenide microstructured optical fibers with low optical losses, due to the broad transparency window of these glasses in the mid-IR, can allow for new breakthroughs in various research fields, e.g. new mid-IR laser sources and mid-IR spectroscopy. In this framework, high purity chalcogenide glasses are needed in order to minimize absorption losses. In this study, $\mathrm{Ge}_{10} \mathrm{As}_{22} \mathrm{Se}_{68}$ samples were prepared using a double distillation method, using different combinations of chlorides and metals as getters for the physico-chemical elimination of carbon, oxygen and hydrogen impurities. Comparing the attenuation spectra of the different samples, the choice of the getters seems to be indeed a significant factor in the quality of the glass. A holey fiber has been realized by casting method using the best sample, showing that the method is suitable for this composition and that the attenuation before and after the casting are comparable.
\end{abstract}

Keywords: Chalcogenide glasses, Chemical synthesis methods, Microstructured optical fibers

\section{Introduction}

In the last twenty years the field of chalcogenide glasses has seen increasing interest, thanks to the broad transparency band they exibhit in the mid-infrared, up to wavelengths as high as $20 \mu \mathrm{m}$. This is an extremely interesting region of the light spectrum, and devices able to operate in it can have applications in many fields. In particular, chalcogenide fibers, that can have transmission in the 1-12 $\mu \mathrm{m}$ range [1], can be especially suitable for telecommunications, sensing, imaging and spectroscopy [2,3]. Another important property of chalcogenides is showing one of the highest nonlinear refractive indices among glasses. For example, $\mathrm{n}_{2}$ is around two orders of magnitude larger than the one of silica in sulfides and up to 1000 times larger than the one of silica in glasses based on heavier chalcogens (Se, Te). This high nonlinearity permits to observe nonlinear effects even in short fibers [4-7]. This allows for applications such as slow light (based on stimulated Brillouin scattering) [5], Raman amplification [8], 3R regeneration [8, 9], alloptical switching [10] and supercontinuum generation [11-13]. Of particular interest for nonlinear applications are microstructured optical fibers (MOFs), in which guiding properties are mainly defined by the $\mathrm{d} / \Lambda$ ratio (d: diameter of the holes, $\Lambda$ : distance between the holes)[14]; in this kind of fiber the design can be altered to obtain large core single-mode, endlessly single-mode or polarization-maintaining fibers, as well as to enhance nonlinear properties and manage the chromatic dispersion[15]. Low losses chalcogenide MOFs obtained by using a casting method instead of the more typical stack-and-draw method have been demonstrated [7].

Among chalcogenide glasses, in this work Ge-As-Se ternary glasses were chosen, because of the good compromise between the position of the transparency window (which includes both the telecommunication C-band, around $1.55 \mu \mathrm{m}$, 
and mid-IR wavelengths), the nonlinear refractive index and the improved thermal and mechanical properties given by the addition of Germanium. In particular, the $\mathrm{Ge}_{10} \mathrm{As}_{22} \mathrm{Se}_{68}$ composition has been demonstrated to be stable against crystallization and suitable to develop small core MOFs [16].

As it is well known, when looking towards fiber applications, the intrinsic losses of the material become a much more important matter (the large propagation length of the light magnifies their influence, with important consequences on the width of the transparency wndow and to the heating-related damaage threshold). For this reason it's fundamental to minimize optical losses, and a first step toward this result is producing as pure as possible chalcogenide glasses. In the case of the Ge-As-Se system treated in this paper, this mainly translates in the removal of water and carbon particles as well as of oxygen and hydrogen pollution. Indeed, the presence of oxygen and hydrogen atoms induces intense absorption bands related to the vibrations of $\mathrm{O}-\mathrm{H}, \mathrm{Se}-\mathrm{H}$, and $\mathrm{As}-\mathrm{O}$ bonds, which are centered at wavelengths overlapping with the material transparency window [17, 18]. In order to obtain high purity glasses, a method similar to the one described [19] was used: the syntheses have been performed in vacuum atmosphere in a sealed silica crucible, with the addition of getters, i.e. chemical compounds which purpose is to react with oxygen, carbon and hydrogen and give as byproducts either highly refractory or highly volatile compounds. This allows to use distillation to strongly decrease the amount of hydrogen and oxygen in the glass. The getters used in this physico-chemical process are usually halides for removing hydrogen [20] and metals for removing oxygen[21].

The purpose of this study is to proceed on the road to obtain further optimization of this synthesis procedure by comparing the efficacy of different getters in removing the aforementioned impurities, knowing that the most commonly used are $\mathrm{TeCl}_{4}$ and $\mathrm{Al}$ or $\mathrm{Mg}$ [22-24], with the goal to improve the transmission of microstructured optical fibers based on high purity chalcogenide glasses. Other than the already mentioned common getters, we chose to use in this study also some novel ones: $\mathrm{SeCl}_{4}, \mathrm{SbCl}_{3}, \mathrm{GaCl}_{3}$, being chlorides of elements that can be included in the network of Ge-As-Se glasses without negative effects, and $\mathrm{Zr}$, Ni, which high melting temperature oxides can be removed by distillation.

\section{Experimental}

We prepared different glasses by melt quenching technique in sealed tube with a double distillation to remove impurities: the charge and getters, placed in a sealed silica tube under high vacuum, were heated up to $800^{\circ} \mathrm{C}$ and subsequently quenched in water; after this step, they were annealed at a temperature just below $\mathrm{T}_{\mathrm{g}}$ in order to reduce the internal stress. The charge was prepared with pure elements, nominally germanium $5 \mathrm{~N}$, arsenic $5 \mathrm{~N}$ and selenium $5 \mathrm{~N}$, weighted and inserted in the tube in a glovebox, under inert atmosphere. During the melting of the charge, the reaction of the getters with the impurities occurs: the halides react with hydrogen and carbon, following reactions like the ones presented as an example below (only the initial and final states are shown, intermediate reaction steps are not well understood)

$$
\begin{aligned}
4 \mathrm{Se}-\mathrm{H} & +\mathrm{TeCl}_{4} \rightleftharpoons 4 \mathrm{Se}+\mathrm{Te}+4 \mathrm{HCl} \\
\mathrm{C}+\mathrm{TeCl}_{4} \rightleftharpoons \mathrm{Te}+\mathrm{CCl}_{4} & =42
\end{aligned}
$$

while the metals react with the oxygen in a way similar to the one shown below for the case of magnesium.

$$
\mathrm{As}-\mathrm{O}+\mathrm{Mg} \rightleftharpoons \mathrm{As}+\mathrm{MgO}
$$

The resulting glass underwent a two step distillation, with temperature and duration of the steps in this procedure kept fixed along the different samples prepared for the comparison. The first one happens in a open setup, in connection with a pump actively removing gases (dynamic distillation). The second one is performed in a sealed setup, once again in high vacuum atmosphere (static distillation). A schematic of these processes can be found in Fig. 1. During the dynamic distillation the glass migrates from the hot zone, at a temperature of $600^{\circ} \mathrm{C}$, to the cold zone. Metal oxides and residuals of silica from the crucible, being refractory, do not migrate, while water and hydrohalic acids, being volatile, are sucked into the liquid nitrogen cooled trap by the vacuum pump, and condensate there. The second step removes traces of metal oxides that could have remained inside the glass. After the distillations, the glass was melted, quenched and annealed again with the same procedure used for the first synthesis. This last step is fundamental to homogenize the material, which during the distillations was separated into compounds with different melting temperatures. 
All the silica setups used were made of low $\mathrm{OH}$ content silica $(<3 \mathrm{ppm})$, and were etched with hydrofluoric acid before being used, in order to minimize the addition of further impurities to the glass, especially after the distillations. The glass composition before and after the distillation process was checked with energy dispersive spectroscopy (EDS) measurements. The variations in the stoichiometry, when measurable, were below $1 \%$, and no leftover traces of getters were found in the glass after the distillation.

As for the different getters used in this comparison, $\mathrm{TeCl}_{4}, \mathrm{SeCl}_{4}, \mathrm{SbCl}_{3}, \mathrm{GaCl}_{3}$ were chosen as halides, while as metals $\mathrm{Mg}, \mathrm{Al}, \mathrm{Zr}$ and $\mathrm{Ni}$ were used. The ratio between the mass of both getters (one halide and one metal for each sample) and the total mass of glass is kept fixed along all the samples. Specifically, each sample contains $2000 \mathrm{ppmw}$ of hydrogen getter and 200 ppmw of oxygen getter. It is to be noticed that hydrogen getters used are all chlorides of elements well compatible with the chalcogenide glass network. Thanks to this and to the low concentration, those elements should not affect the optical properties in case they entered the glass during distillation.

In order to see the effect of the purification, the so-obtained glasses were then drawn in $125 \mu \mathrm{m}$ fibers, the attenuation of which was measured by cut-back technique on a Bruker Tensor 37 FTIR spectrometer using an external liquid nitrogen cooled MCT detector. For each measurement two cut-backs were performed: one with a long part of fiber for the measurement of the low (background) attenuation and one with a short length of fiber for the measurement of the high (peaks) attenuation. The results of the two measurements were then combined into complete spectra. The error was estimated by comparison of repeated measurements on the same fiber, and like the experiment can be separated in two regimes: an error of about $0.1 \mathrm{~dB} / \mathrm{m}$ for the background, where detection-related sources of error are dominant, and an error of about $5 \%$ for the peaks, where because of the short length of fiber random errors related to the cleaving of the fiber are dominant.

For each combination of getter studied, several syntheses were performed. Only the best results achieved will be shown in this study.

Holey preforms were then obtained by casting method [7] using some of the most promising glasses, and drawn into microstructured endlessly single mode fibers, which were characterized using once again FTIR spectrometry.

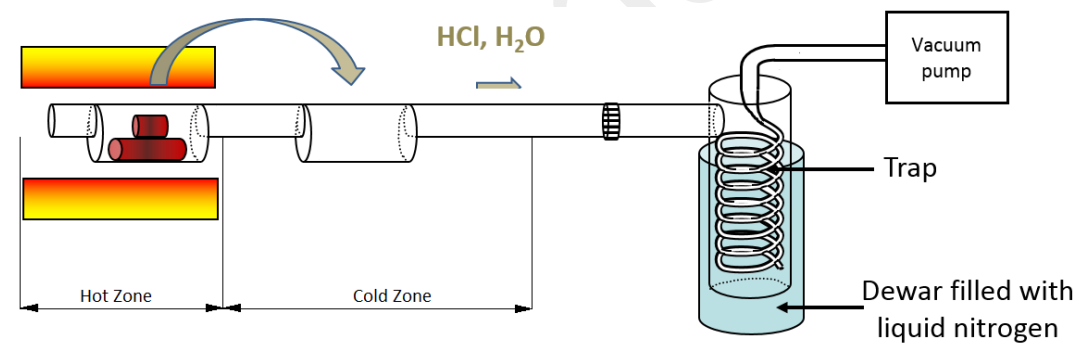

a)

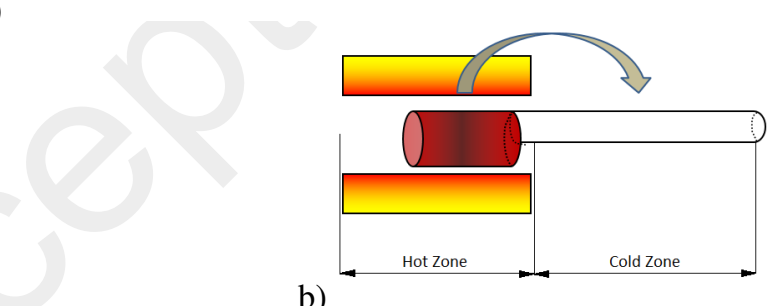

Fig. 1: Schematics of the dynamic (a) and static (b) distillation processes.

\section{Results}

In order to compare the effect of different hydrogen getters on the Se-H absorption peak ( $4.5 \mu \mathrm{m})$, a series of sample was prepared fixing $\mathrm{Mg}$ as the oxygen getter in combination with the different halides listed in Section 2 . In a similar way, a second series was prepared using $\mathrm{TeCl}_{4}$ as an hydrogen getter and the metals listed in Section 2 , with the intention of studying the $\mathrm{Ge}-\mathrm{O}$ and $\mathrm{As}-\mathrm{O}$ peaks $\left(7.9 \mu \mathrm{m}\right.$ and $8.9 \mu \mathrm{m}$ respectively). $\mathrm{Mg}$ and $\mathrm{TeCl}_{4} \mathrm{were}$ chosen as fixed getters for the comparison because their use has already been documented on this composition [16]. The 
measured losses in the transparency windows for the two series are visible in Fig. 2, together with an unpurified glass to show the huge improvements in terms of transmission given by the purification.
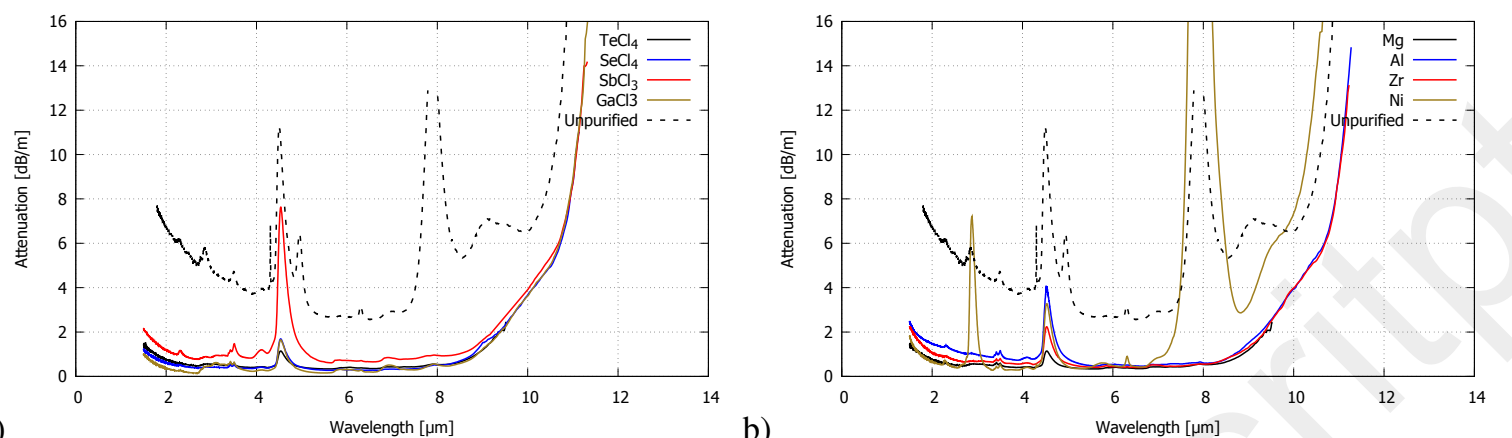

a)

b)

Wavelength $[\mu \mathrm{m}]$

Fig. 2: Comparison between the attenuation spectra of $\mathrm{Ge}-\mathrm{As}$ - Se fibers prepared using magnesium in combination with different hydrogen getters (a) and $\mathrm{TeCl}_{4}$ in combination with different oxygen getters (b). In both graphs, an example of non purified glass is shown.

As it can be seen in Fig. 2.a, all of the halides but $\mathrm{SbCl}_{3}$ appear to be quite efficient in suppressing the Se-H peak. From Fig. 2.b, it can be clearly seen that oxygen-wise $\mathrm{Al}, \mathrm{Mg}$ and $\mathrm{Zr}$ seem to have similar effects, while Ni is not working as an oxygen getter. Indeed, the $\mathrm{Ni}$ containing sample has a Ge-O band comparable with the one of the non-purified glass. Interestingly, the choice of the metal also appears to have influence on the Se-H peak. The peaks at $2.9 \mu \mathrm{m}$ and $6.3 \mu \mathrm{m}$ appearing in the non-purified and $\mathrm{Ni}$-containing samples are assigned to $\mathrm{O}-\mathrm{H}$ and $\mathrm{H}_{2} \mathrm{O}$ respectively. There are no visible carbon-related bands in any of the purified samples. Indeed,in our case carbon impurities are mainly particles, and they therefore induce scattering losses rather than absorption ones.

The combination of $\mathrm{TeCl}_{4}$ and magnesium, which has shown the best results in terms of attenuation, has been chosen as the most suitable for the realization by casting method [7] of a microstructured fiber, of which attenuation spectrum and cross section are visible in Fig. 3. This fiber has an diameter of $125 \mu \mathrm{m}$ and a core diameter of $11 \mu \mathrm{m}$. The holes diameter $(\mathrm{d})$ is $3.4 \mu \mathrm{m}$, while the pitch $(\Lambda)$ is $7.2 \mu \mathrm{m}$, leading to a $\frac{\mathrm{d}}{\Lambda}$ parameter of 0.47 .
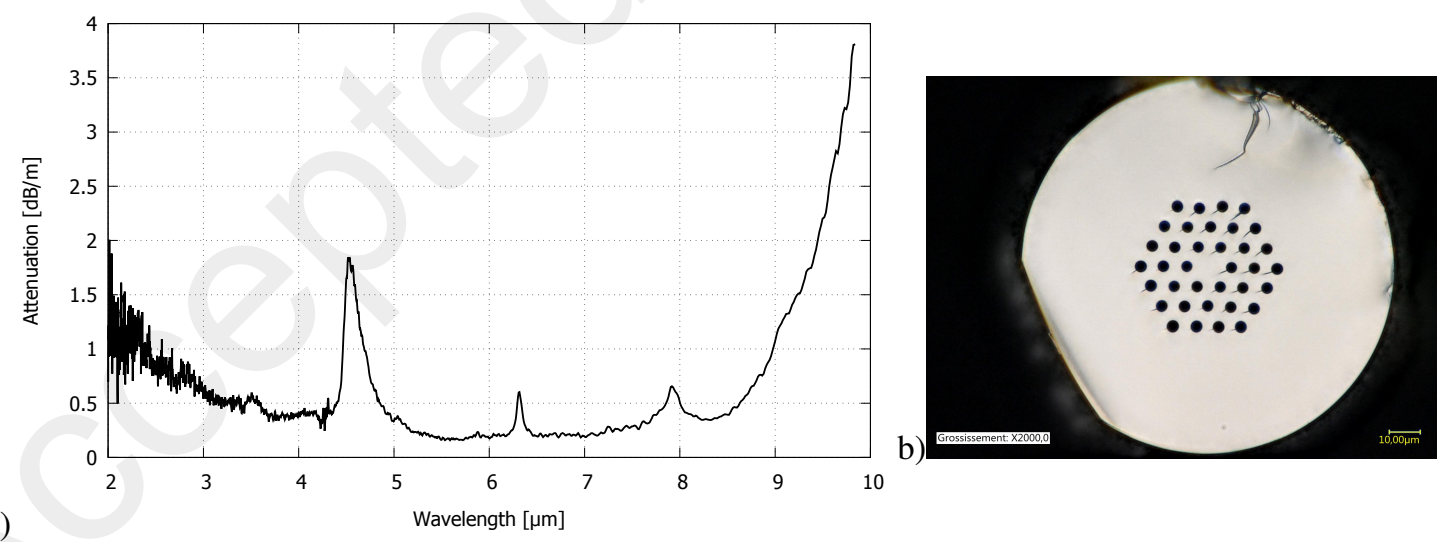

Fig. 3: Attenuation spectrum (a) and cross section (b) of a holey fiber obtained from the sample containing $\mathrm{Mg}$ and $\mathrm{TeCl}$.

\section{Discussion}

Looking at Fig. 2.a, $\mathrm{TeCl}_{4}, \mathrm{SeCl}_{4}$ and $\mathrm{GaCl}_{3}$, reducing the intensity of the $\mathrm{Se}-\mathrm{H}$ peak to a level of around $1.5 \mathrm{~dB} / \mathrm{m}$, seem to be considerably more efficient than $\mathrm{SbCl}_{3}$. In order to better understand the reason of this difference, a starting 
point could be comparing the actual amount of chlorine ions introduced in the melt by the addition of the different halides, for which the mass was kept constant, under the assumption of full dissociation of all the compounds.

Table 1: Molar content of chlorine introduced in the melt by different getters.

\begin{tabular}{|c|c|}
\hline Halide & Cl amount $\left(\mathrm{mol} \cdot 10^{-3}\right)$ \\
\hline $\mathrm{TeCl}_{4}$ & $1.75 \pm 0.15$ \\
\hline $\mathrm{SeCl}_{4}$ & $2.1 \pm 0.2$ \\
\hline $\mathrm{SbCl}_{3}$ & $1.6 \pm 0.1$ \\
\hline $\mathrm{GaCl}_{3}$ & $2.0 \pm 0.2$ \\
\hline
\end{tabular}

No relation between the theoretical moles of $\mathrm{Cl}$ and the efficiency appears to emerge from the values presented in Table 1, with $\mathrm{TeCl}_{4}$ resulting to be the most efficient getter despite the relatively low total amount of chlorine it can introduce in the system. In accordance with the absence of this relation, increasing the mass of the getters didn't bring to better results. Also, comparing the standard Gibbs free energies of the different getters and of $\mathrm{HCl}$ in the range of temperatures [25-27] used during the synthesis, we see no trivial correlation between the stability of these chlorides and their efficiency; on the contrary, in a counterintuitive way the most stable compound, nominally $\mathrm{GaCl}_{3}$ gives better results than the less stable $\mathrm{SbCl}_{3}$. This could be due to different elements in the melt acting as catalysts to favor the reaction in a way similar to the one suggested in [28]; the individuation of the actual reaction steps is far from the goals of this paper, but the fact that the partial elimination of $\mathrm{Se}-\mathrm{H}$ bonds happens even without the addition of any metal to the melt (Fig. 4), a cooperative action of the two getters seems less probable with respect to the action of other glass or crucible components as catalysts.

Concerning the removal of oxygen, Fig. 2.b shows that magnesium, aluminum and zirconium efficiently suppress the $\mathrm{Ge}-\mathrm{O}$ and As-O bands in the attenuation spectra of the respective samples. Nickel, on the other side, seems to be completely ineffective in this regard: as visible in Fig. 4, the spectrum of the Ni containing sample is almost perfectly superimposable with the one of a sample prepared with the same amount of $\mathrm{TeCl}_{4}$, but no oxygen getter. This is compatible with the Ellingham diagrams shown in Fig. 5.a, from which formation of $\mathrm{NiO}$ seem less favored than formation of $\mathrm{GeO}_{2}$, whereas formation of $\mathrm{MgO}$ and $\mathrm{ZrO}_{2}$ appear to be both strongly favored against Germanium dioxide.

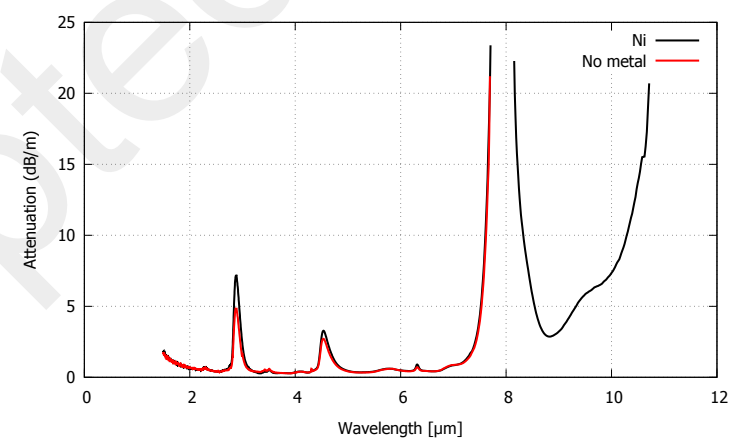

Fig. 4: Comparison between the attenuation spectra of a sample with $\mathrm{Ni}$ as a metal and a sample with no metal at all. In both samples $\mathrm{TeCl}_{4}$ is used as hydrogen getter.

While the choice of the halide doesn't seem here to influence the content of oxides in a relevant way, when comparing the Se-H peaks of the samples prepared with different oxygen getters there is a significant difference. In this case too, the explanation from a reaction dynamics point of view is really complicated and would require deeper studies. Anyway, given the high absolute value of the formation $\Delta \mathrm{G}$ of ternary compounds in the form $\mathrm{M}_{\mathrm{x}} \mathrm{Si}_{\mathrm{y}} \mathrm{O}_{\mathrm{z}}$, with $\mathrm{M}$ being a metal, shown in Fig. 5.b for $\mathrm{Al}, \mathrm{Zr}$ and $\mathrm{Mg}$, it is reasonable to suppose that the oxygen getters can interact with the silica crucible. This could cause the release of hydrogen from $\mathrm{Si}-\mathrm{O}-\mathrm{H}$ groups at the surface of the crucible, 
therefore influencing the amount of hydrogen-related impurities in the chalcogenide glass.

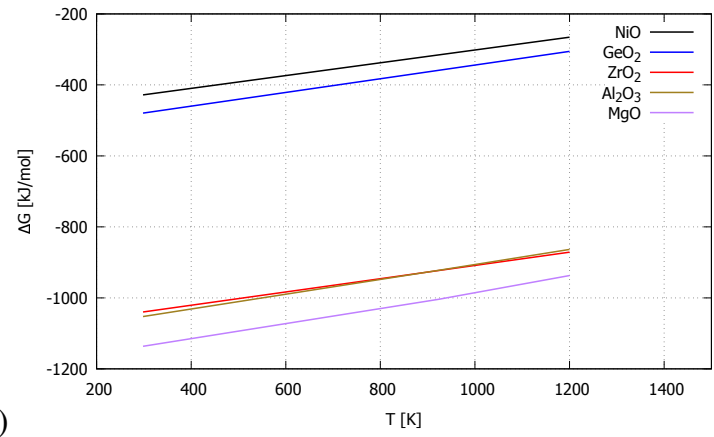

a)

Fig. 5: Ellingham diagrams of different oxygen compounds [25, 26].

b)

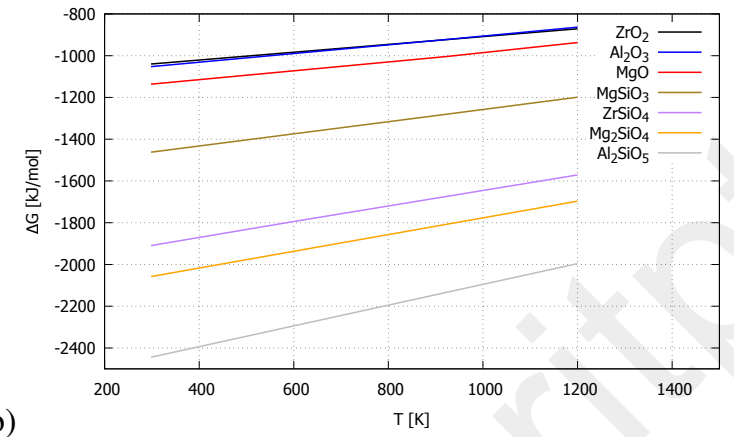


[4] J. M. Harbold, F. O. Ilday, F. W. Wise, B. G. Aitken, Highly nonlinear ge-as-se and ge-as-s-se glasses for all-optical switching, IEEE Photonics Technology Letters 14 (6) (2002) 822-824.

[5] J. S. Sanghera, L. B. Shaw, P. Pureza, V. Q. Nguyen, D. Gibson, L. Busse, I. D. Aggarwal, C. M. Florea, F. H. Kung, Nonlinear properties of chalcogenide glass fibers, International Journal of Applied Glass Science 1 (3) (2010) 296-308.

[6] M. Asobe, Nonlinear optical properties of chalcogenide glass fibers and their application to all-optical switching, Optical Fiber Technology 3 (2) (1997) 142-148.

[7] Q. Coulombier, L. Brilland, P. Houizot, T. Chartier, T. N. N'guyen, F. Smektala, G. Renversez, A. Monteville, D. Méchin, T. Pain, et al., Casting method for producing low-loss chalcogenide microstructured optical fibers, Optics Express 18 (9) (2010) 9107-9112.

[8] R. E. Slusher, G. Lenz, J. Hodelin, J. Sanghera, L. B. Shaw, I. D. Aggarwal, Large raman gain and nonlinear phase shifts in high-purity as 2 se 3 chalcogenide fibers, JOSA B 21 (6) (2004) 1146-1155.

[9] L. Fu, M. Rochette, V. Ta'eed, D. Moss, B. Eggleton, Investigation of self-phase modulation based optical regeneration in single mode as 2 se 3 chalcogenide glass fiber, Optics Express 13 (19) (2005) 7637-7644.

[10] M. Asobe, T. Kanamori, K. Kubodera, Ultrafast all-optical switching using highly nonlinear chalcogenide glass fiber, IEEE photonics technology letters 4 (4) (1992) 362-365.

[11] U. Møller, Y. Yu, I. Kubat, C. R. Petersen, X. Gai, L. Brilland, D. Méchin, C. Caillaud, J. Troles, B. Luther-Davies, et al., Multi-milliwatt mid-infrared supercontinuum generation in a suspended core chalcogenide fiber, Optics express 23 (3) (2015) 3282-3291.

[12] C. R. Petersen, U. Møller, I. Kubat, B. Zhou, S. Dupont, J. Ramsay, T. Benson, S. Sujecki, N. Abdel-Moneim, Z. Tang, et al., Mid-infrared supercontinuum covering the 1.4-13.3 $\mu \mathrm{m}$ molecular fingerprint region using ultra-high na chalcogenide step-index fibre, Nature Photonics 8 (11) (2014) 830.

[13] C. R. Petersen, R. D. Engelsholm, C. Markos, L. Brilland, C. Caillaud, J. Trolès, O. Bang, Increased mid-infrared supercontinuum bandwidth and average power by tapering large-mode-area chalcogenide photonic crystal fibers, Optics express 25 (13) (2017) 15336-15348.

[14] J. Knight, T. Birks, P. S. J. Russell, D. Atkin, All-silica single-mode optical fiber with photonic crystal cladding, Optics letters 21 (19) (1996) $1547-1549$.

[15] G. Renversez, B. Kuhlmey, R. McPhedran, Dispersion management with microstructured optical fibers: ultraflattened chromatic dispersion with low losses, Optics Letters 28 (12) (2003) 989-991.

[16] P. Toupin, L. Brilland, J. Trolès, J.-L. Adam, Small core ge-as-se microstructured optical fiber with single-mode propagation and low optical losses, Optical Materials Express 2 (10) (2012) 1359-1366.

[17] J. Ballato, H. Ebendorff-Heidepriem, J. Zhao, L. Petit, J. Troles, Glass and process development for the next generation of optical fibers: A review, Fibers 5 (1) (2017) 11

[18] M. Churbanov, High-purity chalcogenide glasses as materials for fiber optics, Journal of non-crystalline solids 184 (1995) 25-29.

[19] V. Shiryaev, M. Churbanov, E. Dianov, V. Plotnichenko, J. Adam, J. Lucas, Recent progress in preparation of chalcogenide as-se-te glasses with low impurity content, Journal of optoelectronics and advanced materials 7 (4) (2005) 1773

[20] D. Lezal, J. Pedlikova, J. Gurovic, R. Vogt, The preparation of chalcogenide glasses in chlorine reactive atmosphere, Ceramics 40 (2) (1996) $55-59$.

[21] 张斌, 杨志勇, 任和, 张鸣杰, 章健, 唐定远, Preparation method of high-purity and low-loss chalcogenide glass, cN103332851B (17 2015). URL http: //www.google.it/patents/US4741207

[22] V. Q. Nguyen, J. S. Sanghera, B. Cole, P. Pureza, F. H. Kung, I. D. Aggarwal, Fabrication of arsenic sulfide optical fiber with low hydrogen impurities, Journal of the American Ceramic Society 85 (8) (2002) 2056-2058.

[23] S. Danto, D. Thompson, P. Wachtel, J. D. Musgraves, K. Richardson, B. Giroire, A comparative study of purification routes for as2se3 chalcogenide glass, International Journal of Applied Glass Science 4 (1) (2013) 31-41.

[24] Z. Tang, V. S. Shiryaev, D. Furniss, L. Sojka, S. Sujecki, T. M. Benson, A. B. Seddon, M. F. Churbanov, Low loss ge-as-se chalcogenide glass fiber, fabricated using extruded preform, for mid-infrared photonics, Optical Materials Express 5 (8) (2015) $1722-1737$.

[25] T. B. Reed, Free energy of formation of binary compounds, MIT press, 1971

[26] W. Malcolm Jr, NIST-JANAF thermochemical tables, American Institute of Physics; The American Chemical Society, 1998.

[27] W. M. Haynes, CRC handbook of chemistry and physics, CRC press, 2014.

[28] V. Q. Nguyen, G. Drake, G. Villalobos, D. Gibson, S. Bayya, W. Kim, C. Baker, G. Chin, F. H. Kung, M. I. Kotov, et al., Effect of aluminum and tellurium tetrachloride addition on the loss of arsenic selenide optical fiber, Optical Materials 64 (2017) $327-333$.

[29] V. Shiryaev, S. Mishinov, M. Churbanov, Investigation of adhesion of chalcogenide glasses to silica glass, Journal of Non-Crystalline Solids 408 (2015) 71-75.

[30] S. Mishinov, M. Churbanov, A. Gorokhov, D. Kazakov, V. Shiryaev, A. Suchkov, L. Igumnov, G. Snopatin, Adhesion mechanism of destruction of silica-glass surface during the preparation and treatment of optical glassy arsenic chalcogenides, Inorganic Materials 52 (7) (2016) $716-720$.

[31] M. Churbanov, S. Mishinov, V. Shiryaev, L. Ketkova, Contamination of glassy arsenic sulfide by sio2 particles during melt solidification in silica glassware, Journal of Non-Crystalline Solids 480 (2018) 3-7. 